Original Article

\title{
LinkGenn - SEO and SEM Explorer with Free and Paid Optimum Solutions
}

\author{
Fernando N. ${ }^{\# 1}$, Gunasekara S. ${ }^{\# 2}$, De Silva R. ${ }^{\# 3}$

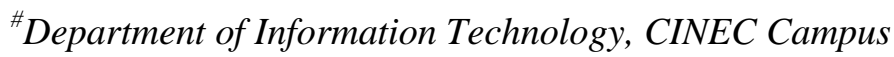 \\ Millenium Drive, IT Park, Malabe, Sri Lanka. \\ Inilanka@linkgenn.com
}

\begin{abstract}
Nowadays with the development of digital platforms digital marketing have been most important thing that every business needs to focus on. This study discusses the review of Search Engine Optimisation (SEO) and Search Engine Marketing (SEM) explorer with free and paid optimum solution tool which is aimed to give a better understanding about digital marketing, SEO site performance which is a must to know before going forward with digital marketing plans. Lack of knowledge in digital marketing has effect small scale to large scale business owners. This tool helps to identify their website performance speed and SEO in understandable way which suggests free and paid optimum solutions. The main purpose of this study is to get more business to LinkGenn by giving better understanding to the customer to identify websites performance problems and suggest free and paid solutions to fix it from their side or with Linkgenn, the entire project develop according to waterfall method. The finding of the study indicated how website performance affecting on digital marketing campaigns, and it uses new developed Linkgenn metrics to give ranking scores and solutions based on website results, with the pandemic lot of businesses have changed their traditional marketing pattern with digital so the site nevertheless the site need to go through web audit and analyse to identify the areas to be fixed to perform well in SEO as it's take
\end{abstract}

this would be an important tool for every business to archive their sales goals with remarkable KPIs.

\section{Keywords: SEO, SEM, Digital Marketing, Web performance, Website Audit}

\section{Introduction}

Having a website is being important in every business and it's play vital role in digital marketing, but just having website without meeting the standards will be a negative fact when perform in digital as more users does not have any idea about website performance. This new comprehensive tool helps to understand the website performance and is all about Search engine optimization audition, it gives an all-analysed report including the features of SEO improvement suggestions, Analytics performance, tips to ranking the website and page speed scoring, mobile page loading time, score to perform Cost Per Clicks(CPC) advertising and overall grading system. Understanding website current state is bit of a critical task, at the first stage of a website as it's hard to ranking in SEO because it takes considerable time search engine algorithms to catch site data and ranking according to site performance and keywords. Many developers does not follow SEO rules when developing months. There are Paid ads but customers are aware from that knowledge in Search Engine Marketing (SEM). There are several new 
metrics base on page insight results and packages will be offered by the tool after understanding the current situation of the website. There are search ads to show website in first few results but that is also based on a bid strategy and the prominence depends on the ad score.

This tool provides a help hand for new business and existing E-commerce business to get a report of their site performance including site loading speed, SEO structure of site, audit report, overall performance of the site and get a summarized report to your email, analysis report which help to identify whether the website is in a level to perform in SEO or not and according to that it helps to build up the site SEO friendly with free suggested tips. For Sri Lanka it is still a new field and lot of people does not have an idea about how to perform their brand on digital world correctly. Therefore, this tool gives main artifact of SEO about explaining each step with a user tip. There are lot of tools in SEO, but it is hard to understand the interpretation for those who does not have an idea about SEO and digital marketing. Therefore, this tool was developed to give a basic understanding about SEO and how to analyse the performance of their own website in digital world with free tips. Moreover, tool suggested plans to who does not know about SEO.

\section{Literature Review}

The purpose of this study is developing successful web site audit tool for digital marketing agency to increase brand awareness, revenue and give an understandable idea of web site performance to the customers, business is mainly catering to B2B segment.

Nicolas has shown thriving website performance using web analytics, in 2013 there were more than 500 websites worldwide [1]. It has made internet a highly competitive environment, which mandated the need of website performance in order to perform among competitors.

With emergence of 2000 analytic tools become strategist element for website optimizing, most website also use web analytics tools to make it efficient for the assessment and optimizing the website, Nicolas research aim to overview website performance and establish list of optimization actions to be implemented, to testing whether there is a positive impact on website performance, with good website performance there have been increased positive traffic and good conversion rate.

Anthony's research has shown limitation and trends in web analytics, as web popularity continues to grow and new uses of the web developed, competitiveness in websites increases and ranking decreases, with the competitiveness. It's must to optimize website performance to perform in SEO, there are many tools have been devised to help access website performance, generally those known as web metrics or indicators used to measure website performance [12].

In order to have good web traffic website performance it is must to maintain good traffic in the website otherwise it will reasoning to have higher bounce rate, Nelson Norman group research article of "How long users stay on web page" shows $45 \%$ of visitors expect to website load in less than 2 seconds [10]. Web analytics could not check prior to the web so performance only can check through.

Digital marketing is a component of marketing which utilized internet and online based digital technologies there are many ways of reaching customers in digital. Such as Content 
marketing, web marketing, SEM, Email marketing, SMM and more [5].

Sarah Silvia shows the importance of digital marketing, in today's world social media and digital marketing activities are very important, it's not only for gaining revenue it also reduces the cost of marketing activities, also digital marketing can track competitive brands how they are doing their activities on digital marketing. There are many advantages of using digital marketing as it can track all the records and in the cost apparently is lower than other traditional marketing methods, with digital and social media activities, able to track people's behaviour and create a database for marketing purposes. The advertisement can be targeted directly to the specific age, gender, location, and even their shopping patterns and lifestyle. Using digital platforms, it eases to know business consumers' profiles. Assessing competitor information will also be also easier than past marketing activities [6].

Google has found more than $50 \%$ of mobile site visitors will leave if the webpage doesn't load within three seconds so that will reason to charge CPC amount and higher bounce rate and no conversions, [7] that may reasoning to decrease business revenue, [4] and SEO ranking also depends on the site audit scores.

In these days lot of people tend to do websites but that does not mean the site has optimized and well-structured Therefore, factors that are affecting with that, it is necessary to be concerned about minimal text on website for good content attention, infographic explanations rather than the text, short paragraph, use of 72dpi resolution images, think about how navigate through the page, simply the navigation, optimize design for the mobile and monitor the page load speed and reduce the loading time to lesser than 4 seconds [7].

The performance of a website is affected by many factors such as networks, server, website platform, and end user. Performance Test gives an idea of the application's response to different loads or stresses. It depends on response times, results and reliability levels that meet website performance targets. The load test describes that if more than one person asks the same data can the system retrieves the appropriate result to users or not in the allotted time [2]. A website should manage user's requests, input data, database connectivity as well as a heavy load on data. Stress tests describe how a website reacts beyond its limit. Stress testing is used to distract the main functionality of the website [5].

Proper SEO helps to enhance the visibility of website in the search engines search results, therefore well perform on SEO Adjustment on keywords, proper website indexing and ensuring the site content is unique that will help to better ranking on SEO[8]. SEM is an approach of a digital marketing, those are paid advertisements appear on search engine result pages, Keyword Bid strategy is using to rank the ad and cost[8].

When it is comes to discuss about SEO \& SEM there should need to explore about organic search and paid search separately. Organic search traffic comes from the people findings business links among the search engine results there for SEO optimization influence the organic search results. Paid search traffic is assigned from visitors clicking on a link in an advertisement or sponsored listing has the business has paid for the search engine to appear at the top results.

Both organic and paid search characterize the visit originated from a click on search engines such as Google, Bing, Yahoo, etc. Organic 
search provides free traffic to the business website while paid search ads are involves fee for click for the form that payment can be charged for click or conversions. By knowing the key search terms will help to decide keywords which is helping to perform on paid campaign and ranking on SEO as well.

Organic search engine marketing can be divided into two classes one is pay for performance and other once is organic search engine optimization. While organic links are better than sponsored links from a customer perspective. Google Trend is treated as a form of research because it predicts the future in volume customer generated requests.

The organic ranking of the website needs to be improved by search engine optimization, therefor must do structure whole website with SEO standards upload XML file with prioritizing the pages, key words and meta tags on relevant all pages. And it is necessary to maintain and updated good quality content on the website because it exhibits a strong positive correlation with customers value, therefore can say that a positive level of organic search. Search engine optimization can improve the quality of the search engine ranking system with satisfying its visitors [1].

\section{Methodology}

\section{A. Planning}

The primary data collected from research articles that shows there are difficulty in identifying website performance as it takes considerable amount of time and that affect on site SEO ranking.
Secondary data of what can find from other audit tools and google page insights that helps to rethink and create new matrixes for the tool in understandable manner with free and paid suggestions to optimize websites and other advertising performance.

This development of SEO \& SEM free and paid explorer with free and paid solutions idea has identified with the real-world problem which is lack of knowledge in Digital marketing and SEO performance among users. It was also identified lot of people doing digital advertising just to get higher traffic to site but there are lot of factors which must be considered before that. As an example, mobile performance of the site, it may take long time to load mobile view of the website and site owner may not consider that but it's highly affects on performs in SEO and advertising because users will not wait more than 3 seconds for page to load on their 1st visit of the site. So, this tool will help to identify website performance with an audit report which has free and paid solutions.

This section discusses about the development methodologies, tools and technologies that are used to building this system.

B. Requirements gathering and analysis.

1) Google developer Console: Google developer console is a cloud platform which allows to build websites of any scale, application, and service in infrastructure of Google. It's not limited to that which provides android SDK tools and API documentation tool set to implement parts of apps using native code.

2) Google API: Google APIs are application programming interfaces which allow to communicate data with Google servers. Third party apps can use API keys to 
gather data, some Google APIs can be used free of charge up to a certain level.

developing HTML5 \& CSS has been used. (Google insight, 2020)

3) JSON: JSON has so many results of site performance, accessibility, best practice, and SEO but this development only will use understandable most important details only as this is catering to just to have a basic understanding of where their Ecommerce business or website currently in and how they need to improve that.

\section{Design}

This tool helps customers to understand their website current status because lot of people are moving to digital marketing as thinking it is a new trend but that trend came up base on lot of digital strategies therefore understanding where they are now and where they want to be is a must before they find a digital marketing solution this drive customers to identify how they can perform there site in SEO and CPC advertising for higher revenue, the details which collecting from the customer will be using for marketing purposes to update customers.

\section{Implementation}

After the gathered information through literature review and according to the waterfall model time plan, the UI/UX design was done for the resulting dashboard, API integration that uses Google Page Speed API results, and Linkgenn planed matrixed for $4 \mathrm{G}$ speed result, grading system, package planning and automated suggestions based on performance, solutions to improve website performance, Mobile website speed score, overall percentage
There are some APIs use from Google insight to audit websites data and the system is built using Java scripts and PHP. For front-end of performance and finally summary report with emailing facility.

This proposed website has used WordPress for the main website and package designing and for the tool. It has used programming languages and frameworks of AJAX, JS, CSS, PHP and HTML.

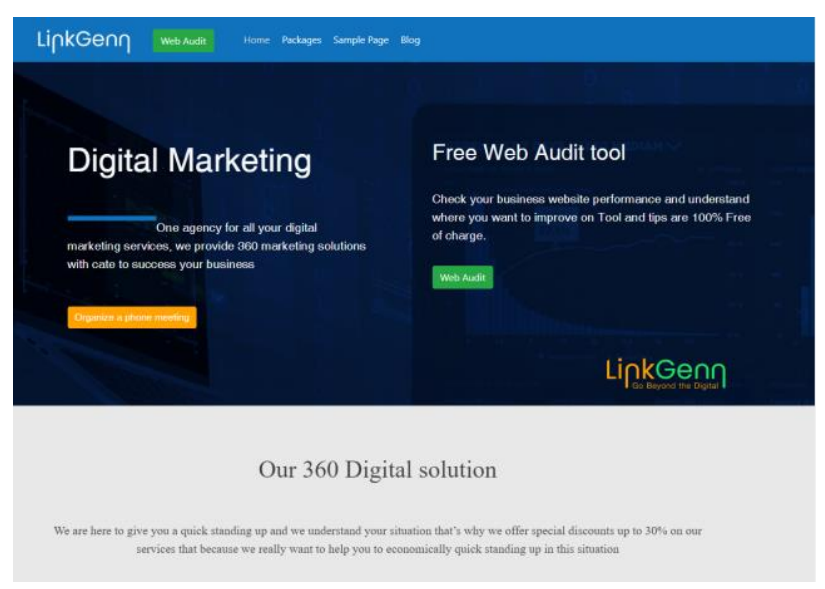

Figure 1 - Website home page

Site home page has information about the 360digital solution, services that are offering and mainly highlighted the web audit tool.

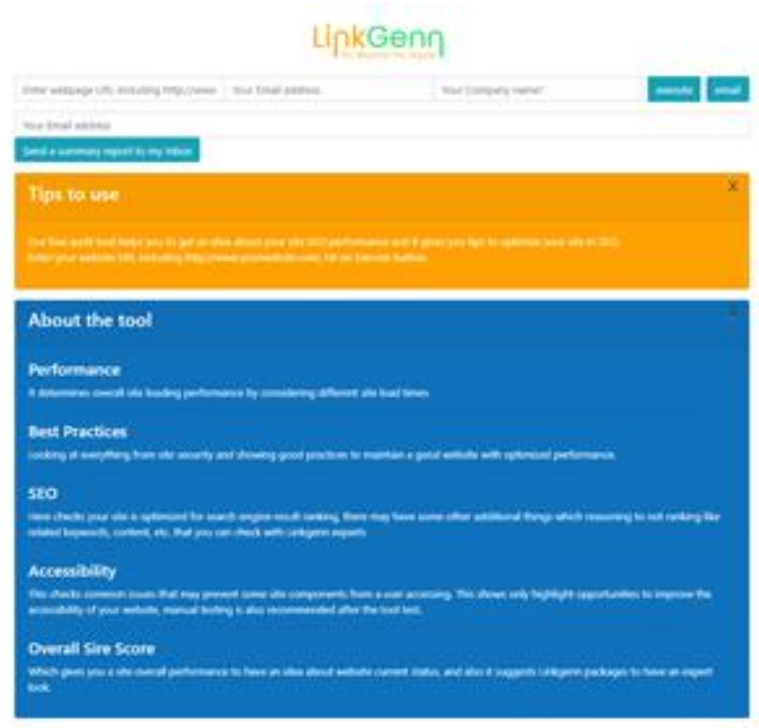

Figure 2 - Tool home page 
Figure 2: in the tool home screen user must enter their website name that needs to scan email address and the company name, and it will take several minutes to load up the full report.

And provide tips as to how to use the tool and about other services.
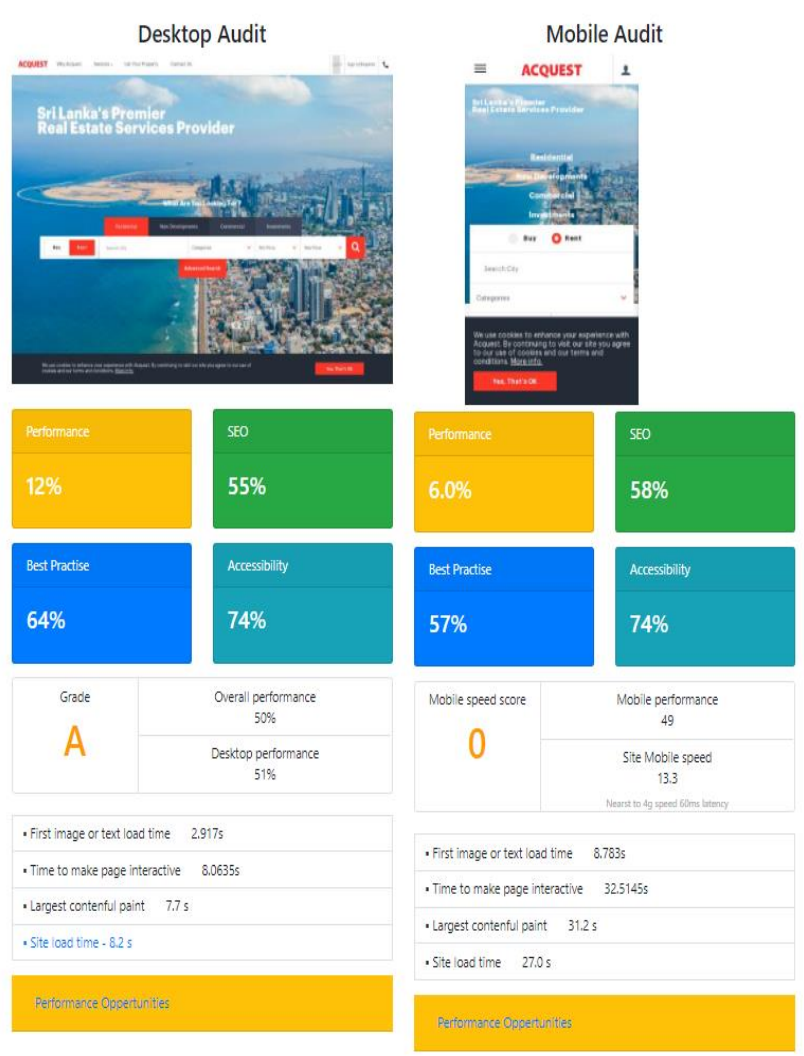

Figure 3 - Analysed audit report (acquest.lk)

The above generated report it shows site performance, SEO performance, best practices of website and accessibility performance. Site grading has been generated with overall score considering all those sub scores and has feature to show website performance in desktop and on mobile. Mobile speed score shows as " 0 " if it takes longer than 12 seconds on $4 \mathrm{G}$ connections, which is not good and immediately need to optimize page for higher performance.

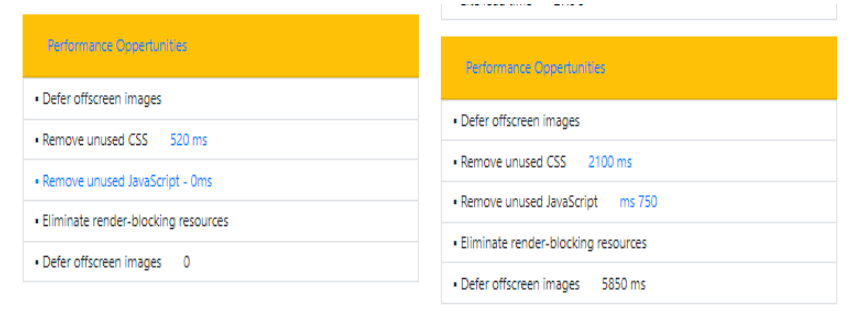

SEO- Content Best Pratices

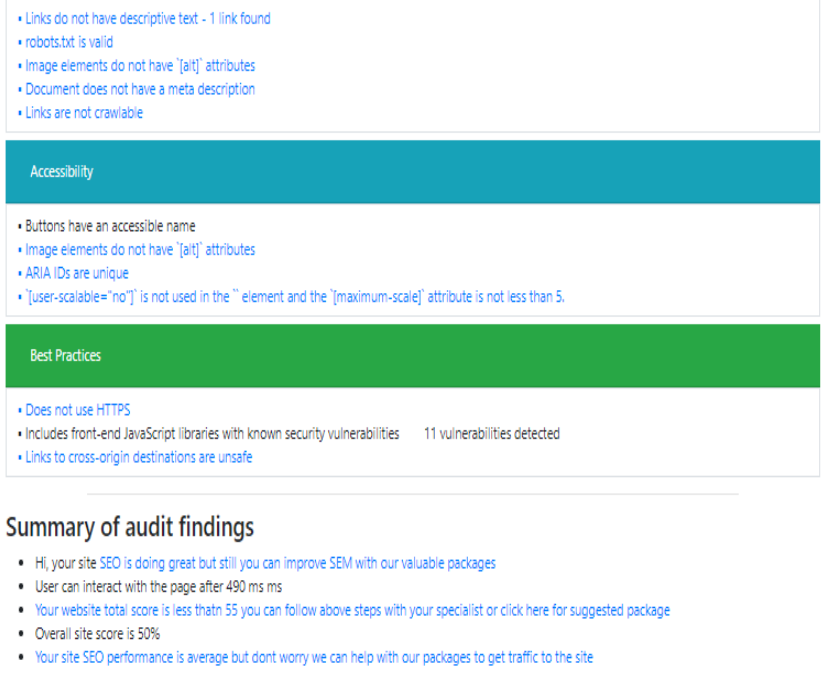

Figure 4 - Summary result with free and paid solutions

Figure 4: shows the suggestions that needs to be done for the optimization of the website for higher score.

Summary section gives you a brief understanding about overall performance and it suggest recomandaded packages to optimize the website. 


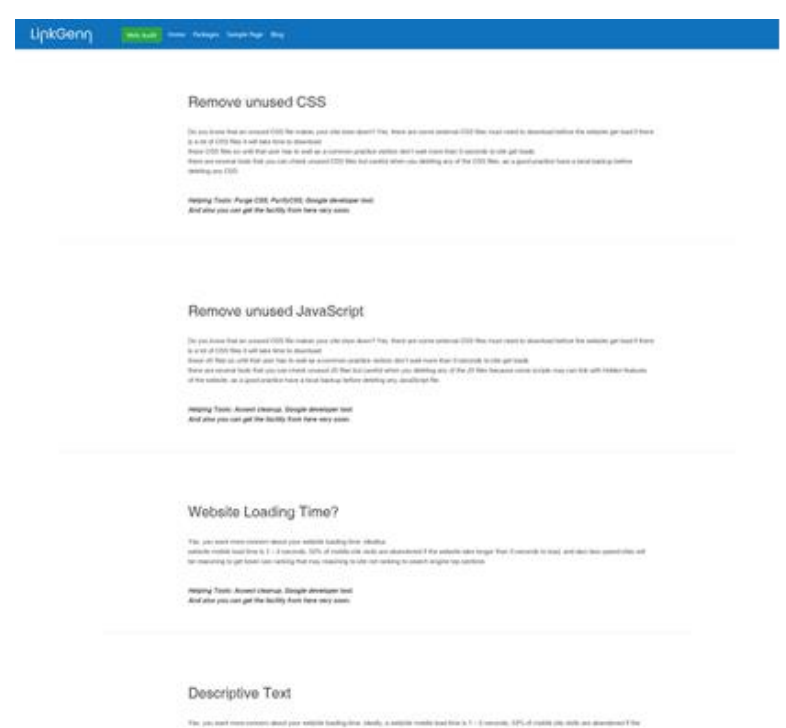

Figure 5 - Free tips to increase website performance.

Figure 5: these free tips are hyperlinked with each section tips so once user click on the problem it shows the ways to fix site performance.
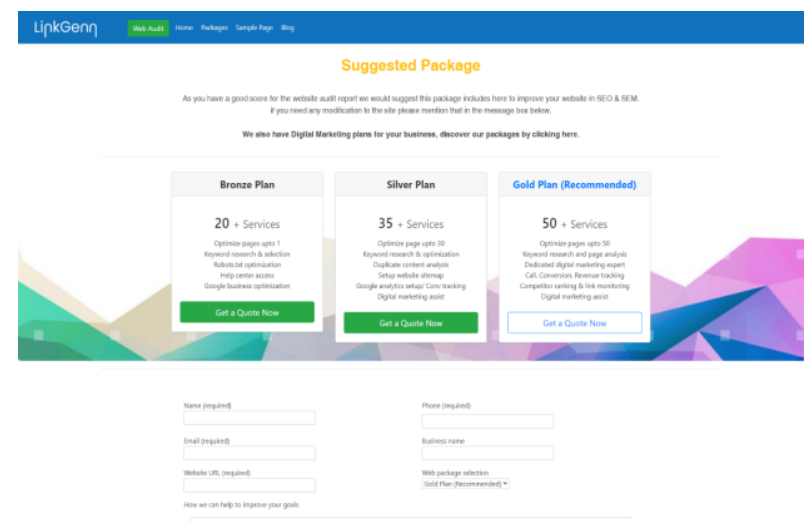

\section{$=$}

Figure 6 - Package suggestions base on performance

Figure 6: System suggested packages based on site performance, it shows the recommended package. Based on the website performance user can select the package and also they can inquire based on their custom requirement.

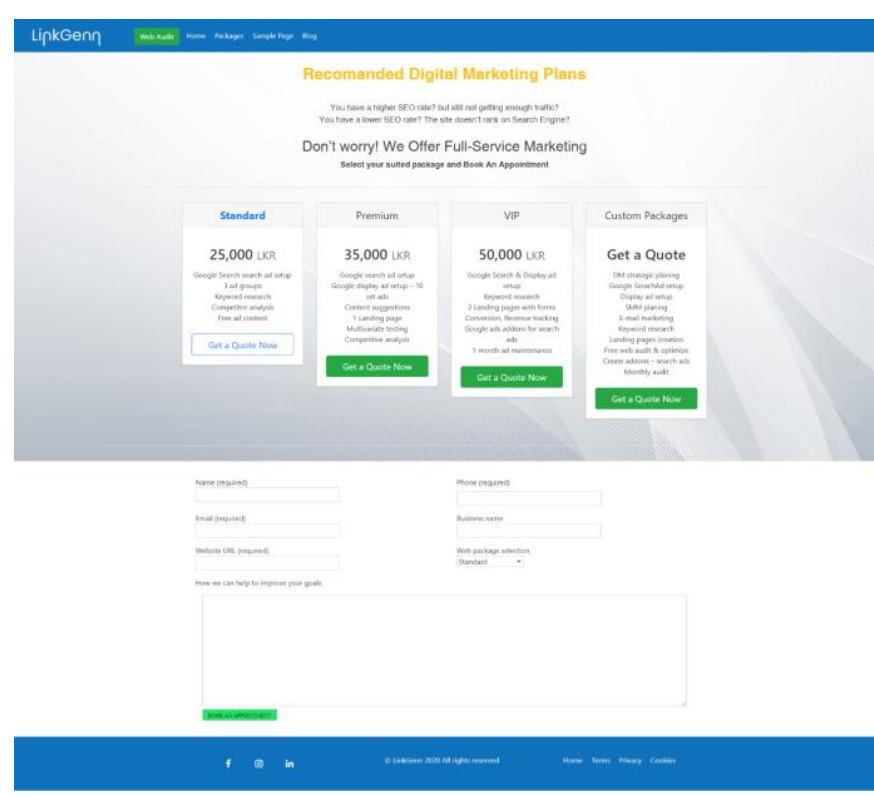

Figure 7 - Digital marketing packages

Figure 7: Shows the digital marketing packages. Those are paid and CPC ads packages, user can select that also based on their requirement and tool suggest which package is more suitable for the website.

\section{E. Testing}

This has gone through several test paces to make matrix values, scores, and grading to confirm with several industry digital marketers and about the suited package selection.

\section{Results and Discussion}

This tool intends website speed and performance, and the generating results that helps to have an idea about their entire website, which will also help digital marketing and web developing industry to analyse their website before finishing up their projects or digital marketing campaigns, which also generates a brief result report with a summary that will be sent to their email.

The tool is live on www.linkgenn.com and able to check any website providing the website link. 


\section{Conclusion}

According to the identified problem with digital marketing, this invented solution for any scale of business, who starting their business on digital with own website but who does not have knowledge in SEO, SEM, site speed, page structure, HTML tags, page load time, robot.txt validation, indexing problems and overall performance., This tool helps to identify website/ landing page performance and find solution for errors which will help to have a successful the digital strategy.

This developed tool identified those technical factors and provided a simple overview of their website before going forward with paid packages.

Ranking in SEO decide on several factors but main considerable factor is site speed, best practices of site, descriptive text, robots.txt file which is help to crawl pages on their website, alt tags, page descriptions, crawlable links, buttons do not have accessible name, image alt tags, user scalable options, HTTPS. All these factors will be considered when SEO ranking. This tools checks all of these factors and give a proper report with the site current situation in a manner which is understandable to any user, by simply clicking on the suggestion it directing to full detailed page of selection which has more details to understand what exactly it's about and way to fix it.

The tool generates scores for website desktop and mobile view performance in site overall speed, SEO, best practice and accessibility if any of score are showing rates in lesser than $60 \%$, those require to be improved with suggestions and score in lesser than $50 \%$ it might need to check the website with suggested solutions and fix immediately to perform the site.
The tool summary of audit findings shows the site health and overall score it tells if the site overall score is lesser than $50 \%$ it tells the site overall performance is very low and suggested paid packages to fix it and it shows free solutions to fix the problem but the expert will only be able to make those changes. Also user can send a summary report to their emails which can be shared with website developer to fix issues if there any, and also suggest some other packages to search engine marketing and social media marketing to increase site traffics, all those links are hyperlinked with each summary points.

Finally, this tool development is success on giving understanding of their websites before starting a digital campaign which helps in understanding a fact why they need to move on with paid advertising where the current site performance is, what are the goals and KPIs that they need to achieve through the campaigns. Usually, only experts consider those factors but LinkGenn, the new invented tool gives understanding to the first who does not have better knowledge in digital marketing performance in SEO, SEM, site performance and traffic generation.

This is not limited to tool it also updates with LinkGenn blog posts and link referrals to gain more organic traffic to LinkGenn website and the tool.

\section{Future implementation}

There are many recommendations for this same tool to improve it with many more features like adding user login to track their website performance with save feature so user can mark everything once there done with the suggested changes so do not miss any suggestions that need to be fix. 
Also, it can add keyword tool to the same for suggest better matching and performing keywords to the website which has to do separate research base on keywords performing in each industry, so the user have to enter the business industry related to which category. So the tool checks the industry ranking keywords from the system data set and shows higher performing keywords to ranking in SEO but it is only limited to 3 for advertising with search ads for adding more keywords it may also suggest Google search ads packages with the starting packages. Those packages can include ads setup costs, free content ad sets, etc.

\section{Acknowledgement}

I express my sincere gratitude to my supervisor Ms. Sachini Gunasekara and Mr.Rajeewa Dharshana. Finally, I would like to thank my classmates, my family members, friends and specially my office staff who supported me.

\section{References}

1) Vieira, V. A. et al. (2019) 'In pursuit of an effective B2B digital marketing strategy in an emerging market', Journal of the Academy of Marketing Science. Journal of the Academy of Marketing Science, 47(6),

2) Kayce Basques (2020) Performance Analysis Reference, Available at: https://developers.google.com/web/tools/ch rome-devtools/evaluate-

performance/reference (Accessed: 20th April 2020).

3) Nor SyamimiSaid. (2014). Review on Web Performance. Medwell Journals.

4) Jon Diorio (2018) Introducing the mobile Speed Scorecard and Impact Calculator, Available

at: https://www.blog.google/products/ads/spee d-scorecard-impact-calculator/ (Accessed: 12th March 2020).
5) Li Kwok, Z. (2018, January 28). DIGITAL MARKETING AND DIGITAL MARKETING STRATEGY. Investopedia. https://www.investopedia.com/terms/d/digi tal-marketing.asp

6) The Importance of Social Media and Digital Marketing to Attract Millennials' Behavior as a Consumer. (2019). Journal of International Business Research and Marketing, 7-8. https://www.researchgate.net/deref/http\%3 A\%2F\%2Fdx.doi.org\%2F10.18775\%2Fjibr m.1849-8558.2015.42.3001

7) Kirkpatrick, D. (2016, September 12). Google: $53 \%$ of mobile users abandon sites that take over 3 seconds to load. Marketing Dive.

https://www.marketingdive.com/news/goo gle-53-of-mobile-users-abandon-sites-thattake-over-3-seconds-to-load/426070/

8) How to Optimize Your Website for SEO and Conversions. (2020, May 13). Crazy Egg. https://www.crazyegg.com/blog/howto-optimize-your-website/

9) Netcraft (2012) March 2012 Web Server Survey, Netcraft http://news.netcraft.com/archives/2012/03/ 05/march-2012-web-server-survey.html

10) Nielsen Norman Group. 2011. How Long Do Users Stay on Web Pages?. [online] Available at: $<$ https://www.nngroup.com/articles/howlong-do-users-stay-on-web-pages/> [Accessed 4 February 2021].

11) Netcraft (2012) March 2012 Web Server Survey, Netcraft http://news.netcraft.com/archives/2012/03/ 05/march-2012-web-server-survey.html

12) Ferrini, A. \& Mohr, Jakki. (2008). Uses, limitations, and trends in web analytics. 124-142. 10.4018/978-1-59904-9748.ch007. 